International Journal of Pure and Applied Mathematics

Volume 111 No. $1 \quad 2016,77-90$

ISSN: 1311-8080 (printed version); ISSN: 1314-3395 (on-line version)

url: http://www.ijpam.eu

doi: $10.12732 /$ ijpam.v111i1.8

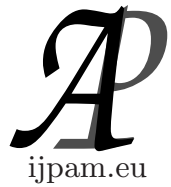

\title{
CONNECTIVITIES FOR A SYMMETRIC PRETOPOLOGY
}

\author{
Monique Dalud-Vincent ${ }^{1} \S$, Michel Lamure ${ }^{2}$ \\ ${ }^{1}$ MEPS - Max Weber Center \\ UFR ASSP - University Lyon 2 \\ 5 Avenue Pierre Mendès-France \\ 69676 Bron cedex, FRANCE \\ ${ }^{2}$ Professor emeritus, \\ University Lyon 1, FRANCE
}

Abstract: In this paper, we present properties of connectivities in the case of a symmetric pretopology.

AMS Subject Classification: 54A05, 54B05, 54B15

Key Words: pretopology, connectivity, symmetry

\section{Introduction}

We already presented how pretopology generalizes both graph theory and topology, see [1], [2], [3]. We also established links between pretopology, matroids and hypergraphs, see [5].

Here, we present results about strong connectivity [3] and connectivity [6] related to a symmetric pretopology.

Received: $\quad$ July 13, 2016

Revised: $\quad$ November 25, 2016

Published: December 6, 2016

$\S_{\text {Correspondence author }}$ (c) 2016 Academic Publications, Ltd.

url: www.acadpubl.eu 


\section{Different Types of Pretopological Spaces, see [1], [2], [3]}

Definition 1. Let $X$ be a non empty set. $P(X)$ denotes the family of subsets of $\mathrm{X}$. We call pseudoclosure on $\mathrm{X}$ any mapping $a$ from $\mathrm{P}(\mathrm{X})$ onto $\mathrm{P}(\mathrm{X})$ such as:

$$
\begin{aligned}
& a(\varnothing)=\varnothing, \\
& \forall A \subset X, \quad A \subset a(A),
\end{aligned}
$$

$(X, a)$ is then called pretopological space.

We can define 4 different types of pretopological spaces.

1. (X, $a$ ) is a $V$ type pretopological space if and only if

$$
\forall \mathrm{A} \subset \mathrm{X}, \forall \mathrm{B} \subset \mathrm{X}, \mathrm{A} \subset \mathrm{B} \Rightarrow a(\mathrm{~A}) \subset a(\mathrm{~B}) .
$$

2. (X, a) is a $V_{D}$ type pretopological space if and only if

$$
\forall \mathrm{A} \subset \mathrm{X}, \forall \mathrm{B} \subset \mathrm{X}, a(\mathrm{~A} \cup \mathrm{B})=a(\mathrm{~A}) \cup a(\mathrm{~B}) .
$$

3. (X, a) is a $V_{S}$ type pretopological space if and only if

$$
\forall \mathrm{A} \subset \mathrm{X}, a(A)=\bigcup_{x \in A} a(\{x\}) .
$$

4. (X, a) a $V_{D}$ type pretopological space, is a topological space if and only if $\forall \mathrm{A} \subset \mathrm{X}, a(a(\mathrm{~A}))=a(\mathrm{~A})$.

Property 2. If $(X, a)$ is a $V_{S}$ space then $(X, a)$ is a $V_{D}$ space. If $(X, a)$ is a $V_{D}$ space then $(X$, a) is a $V$ space.

Example 3. Let $\mathrm{X}$ be a non empty set and $R$ be a binary relationship defined on $\mathrm{X}$. The pretopology of ascendant-descendants, noted $\mathrm{a}_{a d}$, is defined by:

$\forall A \subset X, a_{a d}(A)=\left\{x \in X / R^{-1}(x) \cap A \neq \varnothing\right.$ and $\left.R(x) \cap A \neq \varnothing\right\} \cup A$.

This pretopology is only $V$ one. 


\section{Different Pretopological Spaces Defined from a Space $(\mathrm{X}, \boldsymbol{a})$ and Closures, see [1], [2], [4]}

Definition 4. Let $(\mathrm{X}, a)$ be a $V$ pretopological space. Let $\mathrm{A} \subset \mathrm{X}$. A is a closed subset if and only if $a(\mathrm{~A})=\mathrm{A}$.

We note $\forall \mathrm{A} \subset \mathrm{X}, a^{0}(\mathrm{~A})=\mathrm{A}$ and $\forall \mathrm{n}, \mathrm{n} \geq 1, a^{n}(\mathrm{~A})=a\left(a^{n-1}\right)(\mathrm{A})$.

We name closure of $\mathrm{A}$ the subset of $\mathrm{X}$, denoted $\mathrm{F}_{a}(\mathrm{~A})$, which is the smallest closed subset which contains A.

$\mathrm{F}^{\prime}{ }_{a}$, the inverse of the closure generated by $a$, is defined by:

$$
\forall \mathrm{A} \subset \mathrm{X}, \quad \mathrm{F}_{a}^{\prime}(\mathrm{A})=\left\{\mathrm{x} \in \mathrm{X} / \mathrm{F}_{a}(\{\mathrm{x}\}) \cap \mathrm{A} \neq \varnothing\right\}
$$

We note $a "=\mathrm{F}_{a} \mathrm{~F}_{a}$ ( $a "$ is the composed of the mapping $\mathrm{F}_{a}{ }_{a}$ and $\mathrm{F}_{a}$ ) and $\mathrm{F}^{\prime}{ }_{a}$ the closure according to $a "$.

Remark 5. $\mathrm{F}_{a}(\mathrm{~A})$ is the intersect of all closed subsets which contain A. In the case where (X, a) is a "general" pretopological space (i.e. is not a $V$ space , nor a $V_{D}$ space, nor a $V_{S}$ space, nor a topological space), the closure may not exist.

Proposition 6. Let $(X$, a) be a $V$ space. Let $A \subset X$. If one of the two following conditions is fulfilled:

$-X$ is a finite set;

- a is of $V_{S}$ type.

Then $F_{a}(A)=\bigcup_{n \geq 0} a^{n}(A)$.

Remark 7. If a is of $V$ type then $\mathrm{a}^{n}, \mathrm{~F}_{a}, \mathrm{a}$ ", $\mathrm{F}^{\prime}{ }_{a}$ also are of $V$ type and $\mathrm{F}^{\prime}{ }_{a}$ is of $V_{S}$ type. If a is of $V_{S}$ type then $\mathrm{a}^{n}, \mathrm{~F}_{a}, \mathrm{a}, \mathrm{F}^{\prime \prime}{ }_{a}, \mathrm{~F}^{\prime}{ }_{a}$ are also of $V_{S}$ type.

Definition 8. Let $(\mathrm{X}, a)$ be a $V$ pretopological space. Let $\mathrm{A} \subset \mathrm{X}$. $a$ ' inverse of pseudoclosure $a$ is defined as follows:

$$
\forall \mathrm{A} \subset \mathrm{X}, a^{\prime}(\mathrm{A})=\{\mathrm{x} \in \mathrm{X} / a(\{\mathrm{x}\}) \cap \mathrm{A} \neq \varnothing\} .
$$

$a^{\prime}$ is a pseudoclosure defined on $\mathrm{P}(\mathrm{X})$. We denote $\mathrm{F}_{a^{\prime}}$ the closure according to $a^{\prime}$ and $\mathrm{F}_{a^{\prime}}^{\prime}$ the inverse of the closure according to $a^{\prime}$ (i.e. of $\mathrm{F}_{a^{\prime}}$ ). We also denote $\mathrm{F}^{\prime \prime} a^{\prime}$ the closure according to $\left(a^{\prime}\right)^{\prime \prime}=\mathrm{F}^{\prime}{ }_{a^{\prime}} \mathrm{F}_{a^{\prime}}$. 
Remark 9. (see [7]) Let (X, a) be a pretopological space. If a is of $V$ type then a' is of $V_{S}$ type.

Definition 10. Let $(\mathrm{X}, a)$ be a $V$ pretopological space. Let $\mathrm{A} \subset \mathrm{X}$.

We define the induced pretopology on A by $a$, denoted $a_{A}$, by:

$$
\forall \mathrm{C} \subset \mathrm{A}, a_{A}(\mathrm{C})=a(\mathrm{C}) \cap \mathrm{A} .
$$

$\left(\mathrm{A}, a_{A}\right)$ ( or more simply $\mathrm{A}$ ) is said pretopological subspace of $(\mathrm{X}, a)$. We denote $\mathrm{F}_{A}^{\circ}$ the closure according to $a_{A}$.

\section{Strong Connectivity and Connectivity in $(\mathrm{X}, a)$, see [1], [2], [7]}

Definition 11. Let $(\mathrm{X}, a)$ be a $V$ pretopological space. Let A a non empty subset of $\mathrm{X}$. Let $\mathrm{B}$ a non empty subset of $\mathrm{X}$.

There exists a path in $(\mathrm{X}, a)$ from $\mathrm{B}$ to $\mathrm{A}$ if and only if $\mathrm{B} \subset \mathrm{F}_{a}(\mathrm{~A})$.

There exists a chain in (X, a) from B to A if and only if $\mathrm{B} \subset \mathrm{F}{ }_{a}(\mathrm{~A})$.

We shall speak about $\mathrm{x}$-connectivity to indicate one of the following types of connectivity:

Definition 12. Let $(\mathrm{X}, a)$ be a $V$ pretopological space.

$(\mathrm{X}, a)$ is strongly connected if and only if $\forall \mathrm{C} \subset \mathrm{X}, \mathrm{C} \neq \varnothing, \mathrm{F}_{a}(\mathrm{C})=\mathrm{X}$.

(X, $a)$ is connected if and only if $\forall \mathrm{C} \subset \mathrm{X}, \mathrm{C} \neq \varnothing, \mathrm{F}_{a}(\mathrm{C})=\mathrm{X}$ or $\mathrm{F}_{a}(\mathrm{X}$ $\left.\mathrm{F}_{a}(\mathrm{C})\right) \cap \mathrm{F}_{a}(\mathrm{C}) \neq \varnothing$.

Proposition 13. (see [1]) Let $(X$, a) be a $V$ pretopological space. (X,a) is strongly connected $\Leftrightarrow \forall A \subset X, A \neq \varnothing, \forall B \subset X, B \neq \varnothing$, there exists a path from $B$ to $A$ in $(X, a)$.

Definition 14. Let $(\mathrm{X}, a)$ be a $V$ pretopological space. Let $\mathrm{A} \subset \mathrm{X}$ with A non empty.

$\mathrm{A}$ is a $\mathrm{X}$-connected subspace of $(\mathrm{X}, a)$ if and only if $\left(\mathrm{A}, a_{A}\right)$, as a pretopological space, is $\mathrm{x}$-connected.

$\left(\mathrm{A}, a_{A}\right)$ is a greatest $\mathrm{x}$-connected subspace of $(\mathrm{X}, a)$ if and only if $\left(\mathrm{A}, a_{A}\right)$ is a $\mathrm{X}$-connected subspace of $(\mathrm{X}, a)$ and $\forall \mathrm{B}, \mathrm{A} \subset \mathrm{B} \subset \mathrm{X}$ and $\mathrm{A} \neq \mathrm{B},\left(\mathrm{B}, a_{B}\right)$ is not a $\mathrm{X}$-connected subspace of $(\mathrm{X}, a)$.

Definition 15. Let $(\mathrm{X}, a)$ be a $V$ pretopological space. Let $\mathrm{A} \subset \mathrm{X}$ with A non empty. 
We note $\left(\mathrm{F}_{a}\right)_{A}$ the closing obtained by restriction of closing $\mathrm{F}_{a}$ on $\mathrm{A} .\left(\mathrm{F}_{a}\right)_{A}$ is such as $\forall \mathrm{C} \subset \mathrm{A},\left(\mathrm{F}_{a}\right)_{A}(\mathrm{C})=\mathrm{F}_{a}(\mathrm{C}) \cap \mathrm{A}$.

$\mathrm{A}$ is a X-connected subset of $(\mathrm{X}, a)$ if and only if $\mathrm{A}$ endowed with $\left(\mathrm{F}_{a}\right)_{A}$ is $\mathrm{x}$-connected.

$\mathrm{A}$ is a $\mathrm{X}$-connected component of $(\mathrm{X}, a)$ if and only if $\mathrm{A}$ is a $\mathrm{X}$-connected subset of $(\mathrm{X}, a)$ and $\forall \mathrm{B}, \mathrm{A} \subset \mathrm{B} \subset \mathrm{X}$ with $\mathrm{A} \neq \mathrm{B}, \mathrm{B}$ is not a $\mathrm{X}$-connected subset of $(\mathrm{X}, a)$.

\section{Symmetric Pretopology}

Definition 16. Let $(\mathrm{X}, a)$ be a pretopological space. $a$ is symmetric if and only if $\forall \mathrm{x} \in \mathrm{X}, \forall \mathrm{y} \in \mathrm{X}, \mathrm{y} \in a(\{\mathrm{x}\}) \Leftrightarrow \mathrm{x} \in a(\{\mathrm{y}\})$.

Remark 17. The pretopology of ascendant-descendants is symmetric.

Proof. We have

$$
\begin{aligned}
y \in a_{a d}(\{x\}) & \Leftrightarrow\left(R^{-1}(y) \cap\{x\} \neq \varnothing \text { and } R(y) \cap\{x\} \neq \varnothing\right) \operatorname{or}(x=y) \\
& \Leftrightarrow\left(x \in R^{-1}(y) \text { and } x \in R(y)\right) \operatorname{or}(x=y) \\
& \Leftrightarrow\left(y \in R(x) \text { and } y \in R^{-1}(x)\right) \operatorname{or}(x=y) \\
& \Leftrightarrow\left(R^{-1}(x) \cap\{y\} \neq \varnothing \text { and } R(x) \cap\{y\} \neq \varnothing\right) \operatorname{or}(x=y) \\
& \Leftrightarrow x \in a_{a d}(\{y\}) .
\end{aligned}
$$

Proposition 18. Let (X, a) be a $V$ pretopological space.

$$
\mathrm{a} \text { is symmetric } \Leftrightarrow \forall x \in X, a^{\prime}(\{x\})=a(\{x\}) .
$$

Proof. If $a$ is symmetric

$$
\begin{aligned}
a^{\prime}(\{x\}) & =\{y \in X / a(\{y\}) \cap\{x\} \neq \varnothing\} \\
& =\{y \in X / x \in a(\{y\})\} \\
& =\{y \in X / y \in a(\{x\})\}(a \text { symmetric }) \\
& =a(\{x\}) .
\end{aligned}
$$

Conversely, if $\forall \mathrm{x} \in \mathrm{X}, a^{\prime}(\{\mathrm{x}\})=a(\{\mathrm{x}\})$, then $\mathrm{y} \in a^{\prime}(\{\mathrm{x}\}) \Leftrightarrow \mathrm{y} \in$ $a(\{\mathrm{x}\})$. So $a(\{\mathrm{y}\}) \cap\{\mathrm{x}\} \neq \varnothing \Leftrightarrow \mathrm{y} \in a(\{\mathrm{x}\})$, and $\mathrm{x} \in a(\{\mathrm{y}\}) \Leftrightarrow \mathrm{y} \in$ $a(\{\mathrm{x}\})$. 
Then $a$ is symmetric.

Proposition 19. Let $(X, a)$ be a pretopological space with a symmetric.

(i) If a is of $V$ type,

$$
\forall A \subset X, a^{\prime}(A)=\left(a^{\prime}\right)^{\prime}(A) \subset a(A) .
$$

(ii) If a is of $V_{S}$ type, $\mathrm{a}^{\prime}=\mathrm{a}$.

Proof. (i) We have

$$
\begin{aligned}
a^{\prime}(A) & =\{x \in X / a(\{x\}) \cap A \neq \varnothing\} \\
& =\left\{x \in X / a^{\prime}(\{x\}) \cap A \neq \varnothing\right\} \text { (see Proposition 18) } \\
& =\left(a^{\prime}\right)^{\prime}(A) \\
& \subset a(A) \text { (see }[7]) .
\end{aligned}
$$

(ii) If $a$ is of $V_{S}$ type, $\left(a^{\prime}\right)^{\prime}=a([7])$ and the result according to (i).

Proposition 20. Let $(X$, a) be a pretopological space with a symmetric. Let $n$ be an integer.

(i) If a is of $V$ type,

$$
\forall A \subset X,\left(a^{\prime}\right)^{n}(A) \subset a^{n}(A)
$$

(ii) If a is of $V_{S}$ type, $\left(\mathrm{a}^{\prime}\right)^{n}=\mathrm{a}^{n}=\left(\mathrm{a}^{n}\right)^{\text {'. }}$

Proof. (i) By using recurrence:

- This is true for $\mathrm{n}=1$ (Proposition 19(i)).

- Let us suppose it is true for $n$. We receive:

$$
\begin{aligned}
\left(a^{\prime}\right)^{n}(A) & \subset a^{n}(A) \\
\left(a^{\prime}\right)^{n+1}(A) & =\left(a^{\prime}\right)\left(a^{\prime}\right)^{n}(A) \\
& \left.\subset a^{\prime}\left(a^{n}(A)\right) \text { (because the property is true for } \mathrm{n}\right) \\
& \left.\subset a\left(a^{n}(A)\right) \text { (Proposition } 19(\mathrm{i})\right) \\
& \subset a^{n+1}(A) .
\end{aligned}
$$

(ii) Obvious because $a=a^{\prime}$ and because $\left(a^{n}\right)^{\prime}=\left(a^{\prime}\right)^{n}$ (Proposition 19(ii) and $[7])$.

Remark 21. Generally speaking, if a is of $V$ type, $a^{n}(A) \neq\left(a^{n}\right)^{\prime}(A)$. 
Exemple 22. Let $(\mathrm{X}, \mathrm{a})$ be a $V$ pretopological space with $\mathrm{X}=\{\mathrm{a}, \mathrm{b}, \mathrm{c}$, $\mathrm{d}, \mathrm{e}, \mathrm{f}\}$ and a the pretopology of ascendant-descendants defined according to data in the following table:

\begin{tabular}{|c|c|}
\hline $\mathrm{x}$ & $\mathrm{R}(\mathrm{x})$ \\
\hline $\mathrm{a}$ & $\{\mathrm{b}, \mathrm{c}, \mathrm{e}\}$ \\
\hline $\mathrm{b}$ & $\{\mathrm{a}\}$ \\
\hline $\mathrm{c}$ & $\{\mathrm{b}, \mathrm{d}\}$ \\
\hline $\mathrm{d}$ & $\{\mathrm{a}, \mathrm{e}\}$ \\
\hline $\mathrm{e}$ & $\{\mathrm{f}\}$ \\
\hline $\mathrm{f}$ & $\{\mathrm{d}, \mathrm{e}\}$ \\
\hline
\end{tabular}

Let $\mathrm{A}=\{\mathrm{a}\}$. \} and

We get $\mathrm{a}^{3}(\mathrm{~A})=\mathrm{a}^{3}(\{\mathrm{a}\})=\mathrm{a}^{2}(\{\mathrm{a}, \mathrm{b}\})=\mathrm{a}(\{\mathrm{a}, \mathrm{b}, \mathrm{c}\})=\{\mathrm{a}, \mathrm{b}, \mathrm{c}, \mathrm{d}$

$$
\begin{aligned}
\left(a^{3}\right)^{\prime}(A) & =\left\{x \in X / a^{3}(\{x\}) \cap A \neq \varnothing\right\} \\
& =\left\{x \in X / a \in a^{3}(\{x\})\right\} \\
& =\{a, b, e, f\}
\end{aligned}
$$

and then $\mathrm{a}^{3}(\mathrm{~A}) \neq\left(\mathrm{a}^{3}\right)^{\prime}(\mathrm{A})$.

Proposition 23. Let $(X$, a) be a pretopological space with a symmetric.

(i) If a is of $V$ type, $\forall A \subset X, F_{a^{\prime}}(A) \subset F_{a}(A)$.

(ii) If a is of $V_{S}$ type, $F_{a^{\prime}}=F_{a}=F_{a}^{\prime}$.

Proof. (i) We receive

$$
\begin{aligned}
F_{a^{\prime}}(A) & =\bigcup_{n \geq 0}\left(a^{\prime}\right)^{n}(A)\left(a^{\prime} \text { is of } V_{S}\right. \text { type) } \\
& \subset \bigcup_{n \geq 0} a^{n}(A) \text { (Proposition 20(i)) } \\
& \subset F_{a}(A) .
\end{aligned}
$$

(ii) $\mathrm{F}_{a^{\prime}}=\mathrm{F}_{a}$ because $a^{\prime}=a$ (see Proposition 19(ii)).

Moreover, $\mathrm{F}_{a}^{\prime}=\mathrm{F}_{a^{\prime}}$ (see [7]).

Proposition 24. Let (X, a) be a $V$ pretopological space. Let $A \subset X$ with A non empty. 
If $\mathrm{a}$ is symmetric then $\mathrm{a}_{A}$ is symmetric.

Proof. Let $\mathrm{x} \in \mathrm{A}$ and $\mathrm{y} \in \mathrm{A}$. Then

$$
\begin{aligned}
y \in a_{A}(\{x\}) & \Leftrightarrow y \in(a(\{x\}) \cap A) \\
& \Leftrightarrow y \in a(\{x\}) \text { and } y \in A \\
& \Leftrightarrow x \in a(\{y\})(a \text { is symmetric }) \\
& \Leftrightarrow x \in(a(\{y\}) \cap A) \\
& \Leftrightarrow x \in a_{A}(\{y\}) .
\end{aligned}
$$

\section{Decomposition of $(\mathrm{X}, a)$ with $a$ Symmetric}

Proposition 25. Let $(X, a)$ be a $V$ pretopological space with a symmetric. Let $\mathrm{x} \in X$ and let $\mathrm{y} \in X$.

There exists a sequence $x_{0}, \ldots, x_{n}$ of elements of $X$ such as $x_{0}=x, x_{n}=y$ with $\forall j=0, \ldots, n-1, x_{j+1} \in \mathrm{a}\left(\left\{x_{j}\right\}\right)$

$\Leftrightarrow$ there exists a sequence $x_{0}, \ldots, x_{n}$ of elements of $X$ such as $x_{0}=x, x_{n}=$ y with $\forall j=0, \ldots, n-1, x_{j+1} \in \mathrm{a}\left(\left\{x_{j}\right\}\right)$ or $x_{j} \in \mathrm{a}\left(\left\{x_{j+1}\right\}\right)$.

Proof. Obvious according to the definition of symmetry.

Corollary 26. Let ( $X$, a) be a $V$ pretopological space with a symmetric.

Let $\left\{C_{i}, i \in I\right\}$ the family of non empty subsets of $X$ such as:

(1) $\bigcup_{i \in I} C_{i}=X$.

(2) $\forall \mathrm{i} \in \mathrm{I}, \forall \mathrm{x} \in \mathrm{C}_{i}, \forall \mathrm{y} \in \mathrm{C}_{i}$, there exists a sequence $x_{0}, \ldots, x_{n}$ of elements of $\mathrm{X}$ such as $x_{0}=\mathrm{x}, x_{n}=\mathrm{y}$ with $\forall \mathrm{j}=0, \ldots, \mathrm{n}-1, x_{j+1} \in \mathrm{a}\left(\left\{x_{j}\right\}\right)$.

(3) $\forall \mathrm{i} \in \mathrm{I}, \forall \mathrm{k} \in \mathrm{I}, \mathrm{i} \neq \mathrm{k}, \forall \mathrm{x} \in \mathrm{C}_{i}, \forall \mathrm{y} \in \mathrm{C}_{k}$, there does not exist a sequence $\mathrm{x}_{0} \ldots \mathrm{x}_{n}$ of elements of $\mathrm{X}$ such as $\mathrm{x}_{0}=\mathrm{x}, \mathrm{x}_{n}=\mathrm{y}$ with $\forall \mathrm{j}=0, \ldots, \mathrm{n}-1$, $\mathrm{x}_{j+1} \in \mathrm{a}\left(\left\{\mathrm{x}_{j}\right\}\right)$ or there does not exist a sequence $\mathrm{x}_{0} \ldots \mathrm{x}_{n}$ of elements of $\mathrm{X}$ such as $\mathrm{x}_{0}=\mathrm{y}, \mathrm{x}_{n}=\mathrm{x}$ with $\forall \mathrm{j}=0, \ldots, \mathrm{n}-1, \mathrm{x}_{j+1} \in \mathrm{a}\left(\left\{\mathrm{x}_{j}\right\}\right)$

Let $\left\{\mathrm{S}_{j}, \mathrm{j} \in \mathrm{J}\right\}$ the family of non empty subsets of $\mathrm{X}$ such as:

1- $\bigcup_{j \in J} S_{j}=\mathrm{X}$

2- $\forall j \in J, \forall x \in S_{j}, \forall y \in S_{j}$, there exists a sequence $x_{0} \ldots x_{n}$ of elements of $X$ such as $x_{0}=x, x_{n}=y$ with $\forall i=0, \ldots, n-1, x_{i+1} \in a\left(\left\{x_{i}\right\}\right)$ or $x_{i} \in a$ $\left(\left\{x_{i+1}\right\}\right)$ 
3- $\forall i \in J, \forall k \in J, i \neq k, \forall x \in S_{i}, \forall y \in S_{k}$, there does not exist a sequence $x_{0} \ldots x_{n}$ of elements of $X$ such as $x_{0}=x, x_{n}=y$ with $\forall j=0, \ldots, n-1$, $x_{j+1} \in a\left(\left\{x_{j}\right\}\right)$ or $x_{j} \in a\left(\left\{x_{j+1}\right\}\right)$

We have $\forall i \in I$, there exists $j \in J, C_{i}=S_{j}$.

Proof. Obvious according to the definitions of $\mathrm{C}_{i}$ and $\mathrm{S}_{j}$ and the Proposition 25.

Corollary 27. Let $(X, a)$ be a VS pretopological space with a symmetric.

Let $A \subset X$ with $A$ non empty.

$A$ is a strongly connected subspace of $(X, a) \Leftrightarrow A$ is a connected subspace of $(X, a)$.

Proof. A is a strongly connected subspace of $(\mathrm{X}, a)$

$\Leftrightarrow \forall \mathrm{x} \in \mathrm{A}$ and $\forall \mathrm{y} \in \mathrm{A}$, there exists a path from $\{\mathrm{y}\}$ to $\{\mathrm{x}\}$ in (A, $\left.a_{A}\right)([5])$

$\Leftrightarrow \forall \mathrm{x} \in \mathrm{A}$ and $\forall \mathrm{y} \in \mathrm{A}$, there exists a chain from $\{\mathrm{y}\}$ to $\{\mathrm{x}\}$ in (A, $\left.a_{A}\right)$ ([5], Proposition 25)

$\Leftrightarrow \mathrm{A}$ is a connected subspace of $(\mathrm{X}, a)([5])$.

Corollary 28. Let $(X, a)$ be a $V_{S}$ pretopological space with a symmetric.

Let $A \subset X$ with $A$ non empty.

$A$ is a greatest strongly connected subspace of $(X, a) \Leftrightarrow A$ is a greatest connected subspace of $(X, a)$.

Proof. Obvious according to Corollary 27.

Remark 29. Generally speaking, if (X, a) is a $V$ pretopological space with a symmetric, $\mathrm{A}$ is a greatest strongly connected subspace of $(\mathrm{X}, \mathrm{a})$ is not equivalent to $\mathrm{A}$ is a greatest connected subspace of $(\mathrm{X}, \mathrm{a})$.

Example 30. Let (X, a) be a pretopological space with $X=\{a, b, c, d, e$, $\mathrm{f}\}$ and a the pretopology of ascendant-descendants defined according to data in the following table: 


\begin{tabular}{|c|c|}
\hline$x$ & $R(x)$ \\
\hline$a$ & $\{b, c\}$ \\
\hline$b$ & $\{a\}$ \\
\hline$c$ & $\{b, d\}$ \\
\hline$d$ & $\{a, c, e\}$ \\
\hline$e$ & $\{c, f\}$ \\
\hline$f$ & $\{e\}$ \\
\hline
\end{tabular}

$S_{1}=\{a, b\}$ and $F_{a}\left(S_{1}\right)=X=F^{\prime \prime}{ }_{a}\left(S_{1}\right)$,

$S_{2}=\{c, d\}$ and $F_{a}\left(S_{2}\right)=X=F^{\prime \prime}{ }_{a}\left(S_{2}\right)$,

$S_{3}=\{e, f\}$ and $F_{a}\left(S_{3}\right)=\{e, f\}$.

Then $\mathrm{F}^{\prime}{ }_{a} \mathrm{~F}_{a}\left(\mathrm{~S}_{3}\right)=\mathrm{F}^{\prime}{ }_{a}(\{\mathrm{e}, \mathrm{f}\})=\mathrm{X}$, so $\mathrm{F}^{\prime \prime}{ }_{a}\left(\mathrm{~S}_{3}\right)=\mathrm{X}$.

We get, for each $\mathrm{j}, \mathrm{F}{ }^{\prime}{ }_{a}\left(\mathrm{~S}_{j}\right)=\mathrm{X}$, then $\forall \mathrm{x} \in \mathrm{X}$ and $\forall \mathrm{y} \in \mathrm{X}, \mathrm{x} \in \mathrm{F}{ }^{\prime}{ }_{a}$ ( \{ $\mathrm{y}\}$ ) and $\mathrm{X}$ is a greatest connected subspace of (X,a) (see [5]).

Moreover, $\mathrm{C}_{1}=\mathrm{S}_{1} ; \mathrm{C}_{2}=\mathrm{S}_{2} ; \mathrm{C}_{3}=\mathrm{S}_{3}$ (because a is symmetric) with $\mathrm{F}_{a}$ $\left(\mathrm{C}_{1}\right)=\mathrm{X} ; \mathrm{F}_{a}\left(\mathrm{C}_{2}\right)=\mathrm{X}$ and $\mathrm{F}_{a}\left(\mathrm{C}_{3}\right)=\mathrm{C}_{3}$.

So $\mathrm{A}=\mathrm{C}_{1} \cup \mathrm{C}_{2}$ is a strongly connected component of $(\mathrm{X}, \mathrm{a})$ and $\mathrm{C}_{3}$ is also a strongly connected component of $(\mathrm{X}, \mathrm{a})$ (see [3]).

In addition, $\mathrm{F}^{\circ}{ }_{3}\left(\mathrm{C}_{3}\right)=\mathrm{C}_{3}$ so $\mathrm{C}_{3}$ is a greatest strongly connected subspace of $(\mathrm{X}, \mathrm{a})([3])$.

Also, $\mathrm{F}_{A}^{\circ}\left(\mathrm{C}_{1}\right)=\mathrm{F}^{\circ}{ }_{A}\left(\mathrm{C}_{2}\right)=\mathrm{C}_{1} \cup \mathrm{C}_{2}$ so we get $\mathrm{A}=\mathrm{C}_{1} \cup \mathrm{C}_{2}$ is a greatest strongly connected subspace of $(\mathrm{X}, \mathrm{a})([3])$.

Consequence: Decomposing a pretopological space (X, $a$ ) of $V_{S}$ type, with $a$ symmetric, into greatest connected subspaces is equivalent to decomposing the pretopological space $(\mathrm{X}, a)$ into greatest strong connected subspaces.

Example 31. Let $\mathrm{X}$ a non empty set and $R$ a symmetric binary relationship defined on $\mathrm{X}$. The pretopology of descendants, noted $a_{d}$, is defined by the following pseudoclosure:

$$
\forall A \subset X, a_{d}(A)=\{x \in X / R(x) \cap A \neq \varnothing\} \cup A \text { with } R(x)=\{y \in X / x R y\}
$$

$a_{d}$ is of $V_{S}$ type and $a_{d}$ is symmetric then decomposing $\left(\mathrm{X}, a_{d}\right)$ into greatest connected subspaces is equivalent to decomposing the pretopological space $(\mathrm{X}$, $\left.a_{d}\right)$ into greatest strong connected subspaces. 


\section{Example of a Particular Symmetric Pretopology}

Proposition 32. Let $(X, a)$ be a pretopological space with as defined by the following pseudoclosure:

$$
\forall A \subset X, \text { as }(A)=\bigcup_{x \in A}\{y \in X / x \in a(\{y\}) \text { or } y \in a(\{x\})\} .
$$

$i$ - as is of $V_{S}$ type.

ii- $\forall x \in X$ and $\forall y \in X$, there exists a sequence $x_{0}, \ldots, x_{n}$ of elements of $X$ such as $x_{0}=x, x_{n}=y$ with $\forall j=0, \ldots, n-1, x_{j+1} \in a\left(\left\{x_{j}\right\}\right)$ or $x_{j} \in a$ $\left(\left\{x_{j+1}\right\}\right)$

$\Leftrightarrow$ there exists a sequence $x_{0}, \ldots, x_{n}$ of elements of $X$ such as $x_{0}=x, x_{n}=$ $y$ with $\forall j=0, \ldots, n-1, x_{j+1} \in$ as $\left(\left\{x_{j}\right\}\right)$.

iii- Let $A \subset X$ with $A$ non empty.

If a is of $V_{S}$ type then $A$ is a strongly connected component of $(X$, as $) \Leftrightarrow$ $A$ is a connected component of $(X, a)$.

Proof. i- $\forall \mathrm{x} \in \mathrm{X}, a_{\mathrm{s}}(\{\mathrm{x}\})=\{\mathrm{y} \in \mathrm{X} / \mathrm{x} \in a(\{\mathrm{y}\})$ or $\mathrm{y} \in a(\{\mathrm{x}\})\}$ then $a_{\mathrm{s}}(\mathrm{A})=\bigcup_{x \in A} a_{s}(\{\mathrm{x}\})$.

ii- $a_{\mathrm{s}}\left(\left\{\mathrm{x}_{j}\right\}\right)=\left\{\mathrm{y} \in \mathrm{X} / \mathrm{x}_{j} \in a(\{\mathrm{y}\})\right.$ or $\left.\mathrm{y} \in a\left(\left\{\mathrm{x}_{j}\right\}\right)\right\}$

then $x_{j+1} \in a\left(\left\{x_{j}\right\}\right)$ or $\mathrm{x}_{j} \in a\left(\left\{\mathrm{x}_{j+1}\right\}\right)$

$\Leftrightarrow \mathrm{x}_{j+1} \in a_{\mathrm{s}}\left(\left\{\mathrm{x}_{j}\right\}\right)$ by definition.

iii- If $\mathrm{A}$ is a strongly connected component of $\left(\mathrm{X}, a_{\mathrm{s}}\right)$

then $\forall \mathrm{x} \in \mathrm{A}$ and $\forall \mathrm{y} \in \mathrm{A}$, there exists a sequence $x_{0}, \ldots, x_{n}$ of elements of A such as $x_{0}=\mathrm{x}, x_{n}=\mathrm{y}$ with $\forall \mathrm{j}=0, \ldots, \mathrm{n}-1, x_{j+1} \in a_{\mathrm{s}}\left(\left\{x_{j}\right\}\right)([3])$.

So $\forall \mathrm{x} \in \mathrm{A}$ and $\forall \mathrm{y} \in \mathrm{A}$, there exists a sequence $x_{0}, \ldots, x_{n}$ of elements of A such as $x_{0}=\mathrm{x}, x_{n}=\mathrm{y}$ with $\forall \mathrm{j}=0, \ldots, \mathrm{n}-1, x_{j+1} \in a\left(\left\{x_{j}\right\}\right)$ or $\mathrm{x}_{j} \in a$ $\left(\left\{\mathrm{x}_{j+1}\right\}\right)$ (by definition of $\left.a \mathrm{~s}\right)$.

Then $\forall \mathrm{x} \in \mathrm{A}, \forall \mathrm{y} \in \mathrm{A}$, there exists a chain from $\{\mathrm{y}\}$ to $\{\mathrm{x}\}$ in $(\mathrm{A}$, $\left.a_{A}\right)([5])$, and then $\mathrm{A}$ is a connected subset of $(\mathrm{X}, a)([5][3])$.

If $\mathrm{A}$ is not a connected component of $(\mathrm{X}, a)$, then there exists $\mathrm{B}, \mathrm{A} \subset \mathrm{B} \subset$ $\mathrm{X}$ with $\mathrm{A} \neq \mathrm{B}, \mathrm{B}$ connected component of $(\mathrm{X}, a)$.

So there exists $\mathrm{B}, \mathrm{A} \subset \mathrm{B} \subset \mathrm{X}$ with $\mathrm{A} \neq \mathrm{B}, \forall \mathrm{x} \in \mathrm{B}, \forall \mathrm{y} \in \mathrm{B}$, there exists a sequence $x_{0}, \ldots, x_{n}$ of elements of $\mathrm{B}$ such as $x_{0}=\mathrm{x}, x_{n}=\mathrm{y}$ with $\forall \mathrm{j}=0, \ldots$, $\mathrm{n}-1, x_{j+1} \in a\left(\left\{x_{j}\right\}\right)$ or $\mathrm{x}_{j} \in a\left(\left\{\mathrm{x}_{j+1}\right\}\right)([5][3])$

Then there exists $\mathrm{B}, \mathrm{A} \subset \mathrm{B} \subset \mathrm{X}$ with $\mathrm{A} \neq \mathrm{B}, \forall \mathrm{x} \in \mathrm{B}, \forall \mathrm{y} \in \mathrm{B}$, there exists a sequence $x_{0}, \ldots, x_{n}$ of elements of $\mathrm{B}$ such as $x_{0}=\mathrm{x}, x_{n}=\mathrm{y}$ with $\forall \mathrm{j}=0, \ldots$, $\mathrm{n}-1, x_{j+1} \in a_{\mathrm{s}}\left(\left\{x_{j}\right\}\right)$ (by definition of $a_{\mathrm{s}}$ ). 
So there exists $\mathrm{B}, \mathrm{A} \subset \mathrm{B} \subset \mathrm{X}$ with $\mathrm{A} \neq \mathrm{B}, \forall \mathrm{x} \in \mathrm{B}, \forall \mathrm{y} \in \mathrm{B}$, there exists a path from $\{\mathrm{y}\}$ to $\{\mathrm{x}\}$ in $\left(\mathrm{X}, a_{\mathrm{s}}\right)([5])$.

We get $\mathrm{B}$ is a strong connected subset of $\left(\mathrm{X}, a_{\mathrm{s}}\right)([3])$, which contradicts that $\mathrm{A}$ is a strongly connected component of $\left(\mathrm{X}, a_{\mathrm{s}}\right)$.

So $\mathrm{A}$ is a connected component of $(\mathrm{X}, a)$.

Conversely, if $\mathrm{A}$ is a connected component of $(\mathrm{X}, a)$, then $\forall \mathrm{x} \in \mathrm{A}, \forall \mathrm{y} \in$ A, there exists a sequence $x_{0}, \ldots, x_{n}$ of elements of $\mathrm{A}$ such as $x_{0}=\mathrm{x}, x_{n}=\mathrm{y}$ with $\forall \mathrm{j}=0, \ldots, \mathrm{n}-1, x_{j+1} \in a\left(\left\{x_{j}\right\}\right)$ or $\mathrm{x}_{j} \in a\left(\left\{\mathrm{x}_{j+1}\right\}\right)([5][3])$.

So $\forall \mathrm{x} \in \mathrm{A}, \forall \mathrm{y} \in \mathrm{A}$, there exists a sequence $x_{0}, \ldots, x_{n}$ of elements of $\mathrm{A}$ such as $x_{0}=\mathrm{x}, x_{n}=\mathrm{y}$ with $\forall \mathrm{j}=0, \ldots, \mathrm{n}-1, x_{j+1} \in a_{\mathrm{s}}\left(\left\{x_{j}\right\}\right)$ (by definition of $a_{\mathrm{s}) \text {. }}$

We get $\mathrm{A}$ is a strong connected subset of (X, as) ([5][3]).

If $\mathrm{A}$ is not a strong connected component of (X, $\left.a_{\mathrm{s}}\right)$.

Then there exists $\mathrm{B}, \mathrm{A} \subset \mathrm{B} \subset \mathrm{X}$ with $\mathrm{A} \neq \mathrm{B}, \mathrm{B}$ strong connected component of $\left(\mathrm{X}, a_{\mathrm{s}}\right)$.

Hence there exists $\mathrm{B}, \mathrm{A} \subset \mathrm{B} \subset \mathrm{X}$ with $\mathrm{A} \neq \mathrm{B}, \forall \mathrm{x} \in \mathrm{B}, \forall \mathrm{y} \in \mathrm{B}$, there exists a sequence $x_{0}, \ldots, x_{n}$ of elements of $\mathrm{B}$ such as $x_{0}=\mathrm{x}, x_{n}=\mathrm{y}$ with $\forall \mathrm{j}=0, \ldots$, $\mathrm{n}-1, x_{j+1} \in a_{\mathrm{s}}\left(\left\{x_{j}\right\}\right)([3])$.

Then, there exists $\mathrm{B}, \mathrm{A} \subset \mathrm{B} \subset \mathrm{X}$ with $\mathrm{A} \neq \mathrm{B}, \forall \mathrm{x} \in \mathrm{B}, \forall \mathrm{y} \in \mathrm{B}$, there exists a sequence $x_{0}, \ldots, x_{n}$ of elements of $\mathrm{B}$ such as $x_{0}=\mathrm{x}, x_{n}=\mathrm{y}$ with $\forall \mathrm{j}=0, \ldots$, $\mathrm{n}-1, x_{j+1} \in a\left(\left\{x_{j}\right\}\right)$ or $\mathrm{x}_{j} \in a\left(\left\{\mathrm{x}_{j+1}\right\}\right)$ (by definition of $\left.a \mathrm{~s}\right)$.

We get $\mathrm{B}$ is a connected subset of $(\mathrm{X}, a)([5][3])$, which contradicts that $\mathrm{A}$ is a connected component of $(\mathrm{X}, a)$.

So $\mathrm{A}$ is a strong connected component of $(\mathrm{X}, a \mathrm{~s})$.

Remark 33. as is symmetric.

Proof. Let $\mathrm{x} \in \mathrm{X}$ and $\mathrm{y} \in \mathrm{X}$.

$a_{\mathrm{s}}(\{\mathrm{x}\})=\{\mathrm{y} \in \mathrm{X} / \mathrm{x} \in a(\{\mathrm{y}\})$ or $\mathrm{y} \in a(\{\mathrm{x}\})\}$ (by definition).

Hence $\mathrm{y} \in a_{\mathrm{s}}(\{\mathrm{x}\}) \Leftrightarrow \mathrm{x} \in a(\{\mathrm{y}\})$ or $\mathrm{y} \in a(\{\mathrm{x}\})$.

$\Leftrightarrow \mathrm{x} \in a_{\mathrm{s}}(\{\mathrm{y}\})$.

Proposition 34. Let $(X$, a) be a $V$ pretopological space. Let $A \subset X$, with A non empty.

Then $(\mathrm{as})_{A}=\left(\mathrm{a}_{A}\right)_{\mathrm{s}}$.

Proof. $\forall \mathrm{C} \subset \mathrm{A}$,

$$
\left(a_{A}\right) s(C)=\bigcup_{x \in C}\left\{y \in A / x \in a_{A}(\{y\}) \text { or } y \in a_{A}(\{x\})\right\}
$$




$$
\begin{aligned}
& =\bigcup_{x \in C}\{y \in A / x \in a(\{y\}) \text { or } y \in a(\{x\})\}(x \in A \text { and } y \in A) \\
& =\left(\bigcup_{x \in C}\{y \in X / x \in a(\{y\}) \text { or } y \in a(\{x\})\}\right) \cap A \\
& =a s(C) \cap A \\
& =(a s)_{A}(C) .
\end{aligned}
$$

Proposition 35. Let $(X$, a) be a pretopological space.

Let $A \subset X$ with $A$ non empty.

(i) If (X,a) is of V type then A strongly connected subspace of ( $X$, as) implies A connected subspace of $(X, a)$.

(ii) If $(X, a)$ is of $V_{S}$ type then A strongly connected subspace of $(X, a s) \Leftrightarrow$ A connected subspace of $(X, a)$.

Proof. (i) A strongly connected subspace of (X,as)

$\Leftrightarrow \forall \mathrm{x} \in \mathrm{A}, \forall \mathrm{y} \in \mathrm{A}$, there exists a sequence $x_{0}, \ldots, x_{n}$ of elements of $\mathrm{A}$ such as $x_{0}=\mathrm{x}, x_{n}=\mathrm{y}$ with $\forall \mathrm{j}=0, \ldots, \mathrm{n}-1, x_{j+1} \in\left(a_{\mathrm{s}}\right)_{A}\left(\left\{x_{j}\right\}\right)$ (see [5])

$\Leftrightarrow \forall \mathrm{x} \in \mathrm{A}, \forall \mathrm{y} \in \mathrm{A}$, there exists a sequence $x_{0}, \ldots, x_{n}$ of elements of $\mathrm{A}$ such as $x_{0}=\mathrm{x}, x_{n}=\mathrm{y}$ with $\forall \mathrm{j}=0, \ldots, \mathrm{n}-1, x_{j+1} \in\left(a_{A}\right)_{\mathrm{s}}\left(\left\{x_{j}\right\}\right)$ (see Proposition 34)

$\Leftrightarrow \forall \mathrm{x} \in \mathrm{A}, \forall \mathrm{y} \in \mathrm{A}$, there exists a sequence $x_{0}, \ldots, x_{n}$ of elements of A such as $x_{0}=\mathrm{x}, x_{n}=\mathrm{y}$ with $\forall \mathrm{j}=0, \ldots, \mathrm{n}-1, x_{j+1} \in a_{A}\left(\left\{x_{j}\right\}\right)$ or $\mathrm{x}_{j} \in a_{A}$ $\left(\left\{\mathrm{x}_{j+1}\right\}\right)$ (see Proposition $32(\mathrm{ii})$ ).

So $\forall \mathrm{x} \in \mathrm{A}, \forall \mathrm{y} \in \mathrm{A}$, there exists a chain from $\{\mathrm{y}\}$ to $\{\mathrm{x}\}$ in $\left(\mathrm{A}, a_{A}\right)$ (see [5])

Therefore A is connected subspace of $(\mathrm{X}, a)$ (see [5]).

(ii) We get equivalences if $a$ is of $V_{S}$ type (see [5]).

Corollary 36. Let $\left(X\right.$, a) be a $V_{S}$ pretopological space.

Let $A \subset X$ with $A$ non empty. The following assertions are equivalent:

(i) $A$ is a greatest strong connected subspace of ( $X$, as);

(ii) $A$ is a greatest connected subspace of $(X$, as $)$;

(iii) $A$ is a greatest connected subspace of $(X, a)$.

Proof. (i) and (ii) are equivalent according to the Corollary 28.

(i) and (iii) are equivalent according to the Proposition 35-ii.

Consequence. Decomposing a pretopological space (X,a) of $V_{S}$ type into greatest connected subspaces is equivalent to decomposing the pretopological space ( $\mathrm{X}, a \mathrm{~s})$ into greatest strong connected subspaces. 


\section{References}

[1] Z. Belmandt, Manuel de prétopologie et ses applications, Hermès, Paris, 1993.

[2] M. Dalud-Vincent, Modèle prétopologique pour une méthodologie d'analyse de réseaux. Concepts et algorithmes, Ph.D. Thesis, Lyon 1 University, 1994.

[3] M. Dalud-Vincent, M. Brissaud, M. Lamure, Pretopology as an extension of graph theory: the case of strong connectivity, International Journal of Applied Mathematics, 5, N0. 4 (2001), 455-472.

[4] M. Dalud-Vincent, M. Brissaud, M. Lamure, Closed sets and closures in pretopology, International Journal of Pure and Applied Mathematics, 50, No. 3 (2009), 391-402.

[5] M. Dalud-Vincent, M. Brissaud, M. Lamure, Pretopology, Matroïdes and Hypergraphs, International Journal of Pure and Applied Mathematics, 67, No. 4 (2011), 363-375.

[6] M. Dalud-Vincent, M. Brissaud, M. Lamure, Connectivities and Partitions in a Pretopological Space, International Mathematical Forum, 6, No. 45 (2011), 2201-2215.

[7] M. Dalud-Vincent, M. Lamure, Connectivities for a Pretopology and its inverse, International Journal of Pure and Applied Mathematics, 86, No. 1 (2013), 43-54, doi: 10.12732/ijpam.v86i1.5. 